\title{
The Research of College English Teaching Reform from Multi Modal Perspective
}

\author{
Xia Wang \\ Foreign Language Teaching and Research Department, JiLin University of Finance and Economics, China
}

Keywords: Multimodal, College English teaching, Reform measures

\begin{abstract}
As an applied language discipline, English is an important subject of university education. The reform of college English teaching based on multi - modal theory has gradually become the mainstream. More and more universities through the multi-modal teaching model to mobilize the students' multi-sensory coordination and cooperation, as well as to improve English learning ability, enhance the purpose of learning. This paper analyzes the concrete measures of English teaching reform from the significance of multimodal theory in college English reform.
\end{abstract}

\section{Introduction}

With further reforms in College English teaching in China, higher requirements have been put forward for the English teaching. And as for basic requirements of listening and speaking, students should be able to communicate in English in the course of learning, such as conducting discussions on a given theme, talking about everyday topics in English, etc. Although the reforms of teaching methods have been made and many long-existing problems have begun to change, there is still a long way to realize the desired outcomes. Generally speaking, most non-English majors' English cannot satisfy the needs of communication in modern society [1].

At present, the new university foreign language teaching idea and the teaching media are becoming more and more abundant, and the teaching method used in the past teaching is urgently needed to be reformed. The college English teaching in the multimodal perspective is in the preliminary development stage of foreign language teaching research, and teachers are required to contact the innovative curriculum resources closely in the classroom. Through the language, video, voice, text and other multi-modal form, it provide students close to the real language learning context, and teaching information into which to cultivate students' language skills and practical ability to achieve the desired teaching effect.

\section{Summary of Multimodal Theory}

Multimodality, as a hot academic topic, is discussed by semioticians and linguists in recent years, and is given different definitions by these researchers. In the field of Social Semiotics, as a field of research, theory, and practice, multimodality considers how different modes of communication work together to create meaning. Besides, it is defined by Kress and van Leuven (2001) as "the use of several semiotic modes in the design of a semiotic product or event, together with the particular way in which these modes are combined...fulfill complementary roles or be hierarchically ordered". What's more, Jewitt (2009) describes multimodality as "approaches that understand communication and representation to be more than about language, and which attend to the full range of communicational forms people use - image, gesture, gaze, posture, and so on - and the relationships between them”. In addition, according to Gu (2007), modality refers to human beings' interaction with the external surroundings (such as people, machines, objects, animals, etc.) Through different senses, and the interaction in which more than two senses are involved can be understood as multimodality. In its most basic sense, multimodality creates meaning based on the use of sensory modalities, such as audio, visual and textual modes[2]. 
Multimodal expression can be divided into two or more single modalities that simultaneously express meaning. Multi-modal discourse through language, image, sound, action and other means carry out language communication through auditory, visual, tactile and other senses. Multimodal theory covers a total of five levels of system: Firstly, the cultural dimension, which involves the ideology of the main form of culture as the genre and the structural potential of the choice as a discourse model. Secondly, the context level, mainly related to cover the specific scope of the discourse, tone and mode, including the context of the structure. Thirdly, the meaning of the level involves the concept of meaning, the seeking articles meaning and the interpersonal meaning.Fourth, the formal level construct a variety of forms of the system, which involves the language of the grammar system, multi-modal expression of the meaning and grammar system and the relationship between multi-modal grammar. Fifth, the media level belongs to the final form of matter in the material field. Multimodal discourse in the form and the media level will further expand the scope of linguistics.

\section{The Role of Multi - modal Theory in College English Teaching Reform}

Multi-modal theory emphasizes the diversity of teaching models, through the use of multimedia video, audio to mobilize the enthusiasm of students. At the same time, the college English teaching under the multimodal theory emphasizes the student's subjectivity, demands and encourages the students to participate in the teaching process. English is practical and stimulates students' subjective initiative to help improve teaching efficiency. From this point of view, the application of multimodal theory has positive significance. In addition, the multi-modal theory emphasizes students' listening, speaking, reading and writing comprehensive ability training, consistent with the demand pattern of talented people in modern society.In short, compared with the traditional model, multi-modal theory has obvious advantages, which main role is reflected in the following: (1) Promoting the reform of college English teaching and optimizing the effect of classroom teaching. (2) Improving the efficiency of college English teaching and cultivating college students' ability to read, speak and write.

The significance of multimodal teaching theory in college English teaching is mainly reflected in the following points: (1) Multimodal teaching is the need for global cultural pluralism and communicative multimodal development. (2) Multi - modal teaching is the key to deepen the reform of college English teaching and improve the quality of college English teaching. (3) Multi - modal teaching theory is an effective way to cultivate college students' ability of listening, speaking, reading and writing and autonomous learning. Therefore, the application of multimodal theory in college English teaching has positive significance [3]. The teaching model under this theory should be paid attention to by the relevant teaching staff, and combined with the development of the university itself and the needs of students to implement this teaching model.

\section{Specific Measures of College English Reform in Multi - modality}

Reform the teaching materials. The rapid development of information technology will be the traditional expression of words and visual, auditory and other ideographic form of organic combination. Most of the original printed textbooks are used in the form of text, which is a single modal form of information transmission, and multi-modal textbook has the characteristics of large information capacity, mainly through advanced multimedia technology to video, sound, animation, images and so on a variety of modal forms to impart knowledge to students, to mobilize students interest in learning English, to improve students' enthusiasm for teaching activities, the use of all-round multi-sensory experiential learning to achieve the desired teaching effect, scientific and innovative curriculum resources.

Firstly, it's the basic knowledge of language. Through the combination of audio and text of the multi-modal form to show the words of college English textbooks, the use of standard voice demonstration for students to practice, follow, compare and imitate, so that you can send the correct voice, tone, rate. For some difficult long sentences and knowledge points, should be used to match the 
text, video, animation and other forms to help students in a timely manner to understand and understand the system to develop a comprehensive and innovative teaching content, students can also be based on their own English level clearly adapt content, so as to meet the language level established in the teaching objectives.

Secondly, it's the chapter structure. Through the genre characteristics and interactive forms achieve multi-modal chapter structure. On the one hand, the magazine, the film, the newspaper, the advertisement and the related content in the network combined with the introduction of the English chapter structure, the use of video, text, images and many other hypertext information form, some of the frequent form and its stylistic features detailed explain, such as clarity, argumentative essays, narrative and other applied style, to ensure students' effective learning in the real context.

Finally, it's the cultural background. From the cultural level analysis, the use of video, text, images and other multi-modal form, reflecting the cultural knowledge, values, background information, for the importance of language communication, create a vivid language learning environment, so that students can The environment, feel the colorful world. When students have a strong desire for knowledge and curiosity, they will be deeply aware of and learning knowledge [4]. Creating close to the real language learning environment can make students realize that language learning is an important platform to experience and perceive foreign culture and colorful world, promote the formation of self-learning consciousness, give full play to its subjective role and strengthen its autonomous learning ability, to ensure the high efficiency of language learning, and towards the people-oriented teaching philosophy direction to evolve rapidly.

Reform the design of teaching activities. The arrangement of teaching activities is the focus of English teaching, and the implementation of multidimensional teaching activities completely abandons the traditional teaching methods, which will improve the students' ability of language communication as the main goal. Teachers should give full play to the leading role, clear the students' classroom status, teaching and learning organic integration and common development and create benefits.

1) Experience the design of activities. Teachers create close to the real language learning situation, such as the film or animation for the film dubbing, play the role of the works and students according to their own English level clearly suitable for their own content, such as an animation, video and so on. In the case of Ways to Success, the second part of the fifth edition of the College English Experience, the students are asked to imitate an interview with Bill Gates or Michael Jordan. Let the students show in groups, and establish an exemplary dialogue to illustrate. Students can show the process of a comprehensive, more sensible to master the language knowledge, improve oral expression and language skills, so as to experience the profound experience of language learning.

2) The design of practical activities. Teachers can be divided into several groups of students, and asked the group to use spare time through multimedia technology for video, sound, images and other forms of multi-modal implementation of a personalized combination, and actively into the film and television drama, English advertising and other aspects of the production Activity, and in the classroom play themselves' works with video, audio, animation. For example, teachers in the teaching of "college experience English" third volume of the first unit Caring for Our Earth, so that students through the group form, a comprehensive access to environmental protection and many of the original English material, and on this basis, product English promo about environmental protection. In the classroom, teachers and students collaborate to analyze the success or failure of the work, and actively encourage students to share their own experience in the class, and constantly improve their English level.

3) The design of language expression activities. In the process of teaching, teachers should carry out group debates, song concerts, English lectures and other activities to develop students' good oral expression and language skills. For example, the teaching of "University of English," the third volume of the third unit The Pros and Cons of Famous Brands, brand name for the title in the classroom to carry out the relevant debate. During the debate, the teacher should ask questions in a scientific way, guide the students to think deeply, and give the appropriate praise or reward to the students who perform well. This activity not only helps students to understand the relevant language 
information learn the knowledge of language and culture, but also make students have a positive sense of language learning, and strive to complete the language learning objectives[5].

4) The design of integrated activities. Multi-modal network learning resource platform can achieve a variety of teaching activities. Teaching and discussion activities, students can video, audio and other forms of network platform and some of the learners, professionals to communicate, exchange and explore, to master the various objects under the way of thinking and thinking, teachers can integrate into the student's dialogue and Discuss activities to help students solve difficult problems. This not only makes the teachers and students form a rich life experience, establish a scientific value concept, but also improve the teachers and students to participate in teaching activities of the enthusiasm and enthusiasm to promote the effectiveness of language learning, entertaining, abandon the traditional using too rigid, dogma teaching mode.

Reform Teaching Management and Teaching Evaluation. Teaching management and teaching evaluation not only refers to the management and evaluation of teachers, but also the evaluation and management of teachers.

On the one hand, in the multi-modal "college English" teaching environment, school administrators should encourage teachers to improve their quality and ability, and give teachers more opportunities to learn, to timely training of teachers to continuously improve its teaching method. The teaching evaluation of teachers should also take a variety of forms, not only the evaluation of teachers' lesson preparation, job correction and other circumstances, more importantly, to assess the teacher in the classroom teaching process is called a variety of modal, The use of discourse symbols, whether in the teaching process using images, animation, video, audio, eyes, expressions, gestures, body language and other symbols [6]. Whether the interaction between teachers and students is effective, whether there is any interaction with the body language, and whether the interaction is appropriate. To practice lectures, teachers at any time in the classroom lectures, requiring teachers to collect lessons, to be held in a timely manner demonstration classes, open classes and mutual assessment, teachers should be more between the teaching experience of the exchange and interaction.

On the other hand, teachers' teaching evaluation of students also needs to be reformed. Based on the video input method and audio input method mentioned in the course of implementation, the teacher's ability to evaluate the language ability of students in multimodal college English teaching can not only study the effect of language input, but also examine its nonverbal factors Can be from the voice of the tone, body language and other aspects of reproduction of language materials. Therefore, the evaluation consists mainly of two parts, namely, the stage assessment and the final evaluation. Teachers according to the level of language development of students, participation and the performance of the group in the exchange of records of academic performance give students timely feedback. Termination Assessment On the basis of traditional written tests, students' video and audio materials are entered to examine the knowledge and ability of students to listen, read, write and translate nonverbal factors. This kind of evaluation standard is based on the multi-modal discourse theory on the symbolic meaning of the function of the development of a comprehensive ability evaluation system, embodies the ability to cultivate students' language application ability of college English teaching objectives.

\section{Summary}

To sum up, college English teaching cannot be ignored in an important content is the cultivation of students' English ability. How to improve the application ability of college students in English practice and the English into the future work of the main communication tools is the modern university English teaching research in the core direction. With the advent of the multimodal era, the multimodality of college English classroom has received wide attention. Multi-modal teaching is the product of the development of the times, but also the inevitable result of college English teaching reform. Multi-modal teaching mode requires English teachers to make full use of multi-dimensional teaching methods, reasonable call, coordinated handling, to build a reasonable teaching mode. 
At the same time the implementation of multi-modal English teaching can narrow the distance between teachers and students, good interaction, to achieve teachers and students to learn the progress of the classroom atmosphere. In the process of teaching, teachers should fully understand the function of multimodal teaching, use the multi-modal information transmission mode, create a close to the real language environment, to mobilize the sensibility of the teaching subject to ensure the effective integration of external and internal factors , To improve the teachers and students to participate in teaching activities of interest, to complete the final teaching objectives and teaching results, to develop students to form autonomy, exploration and cooperation of the good spirit, to achieve the purpose of learning. Therefore, it is necessary and meaningful to apply multimodal theory to local college English teaching practice.

\section{Acknowledgement}

Thanks to the joint efforts of the members of Jilin University of Finance and Economics; Thanks to the funding of Jinlin Province for "the 13th Five-Year Planning" on Education and Science ; thanks to the support of JiLin Higer Education Society. This paper is a series of Paper Programs Research on the Exploration and Promotion of Language Education Informatization in Multimodal Perspective (NO:GH170328)Research on College English Teaching Reform From Internet Plus multi modal Perspective (NO: JGJX2017D107) Research on the Application of University Open Course in Cloud Computing Environment (NO: JJKH20170145SK).

\section{References}

[1] Y.S. Zhu, The Theoretical Basis and Research Method of Multi - modal Discourse Analysis, Journal of Foreign Languages, 2007, vol.5, pp.15 -17.

[2] D.L. Zhang, The Application of Multi - modal Discourse Theory and Media Technology in Foreign Language Teaching, Foreign language teaching, 2009, vol.4, pp.28-32.

[3] H.L. Zhou, Teacher - student Interaction in Multi - modal College English Classroom Teaching,Teaching research, 2012, vol.2, pp.96-99.

[4] Q. Liu, A Study on English Nonverbal Communication Ability of Chinese College Students in Multi - modal Environment, Foreign Language Teaching, 2010, vol.3, pp.54-57.

[5] Y.Wang, Multilingual interactive teaching mode in multimedia English writing teaching, foreign language teaching, 2010, vol.11, pp.8-11.

[6] Q.H. Wei, Multi-modal and college students multi-literacy ability research, foreign language teaching, 2009, vol.2, pp.34-37. 